\title{
Sacolas retornáveis: uma alternativa para redução do impacto de larga escala causado pela eliminação irregular de sacolas descartáveis
}

\author{
Reusable bags: an alternative to reduce the impact of large scale caused by the elimination of \\ irregular disposable bags \\ Cláudia Bach Rizzatti', Juliana Benitti Lorenzett² ${ }^{2}$ Daniel Benitti Lorenzett ${ }^{3}$, Leoni Pentiado Godoy ${ }^{4}$ \\ 1,3Mestre em Engenharia de Produção, Universidade Federal de Santa Maria, Santa Maria, Brasil \\ ${ }^{2}$ Colégio Politécnico da UFSM, Universidade Federal de Santa Maria, Santa Maria, Brasil \\ ${ }^{3}$ Prof $^{a}$ Dra $^{a}$ do Programa de Pós-Graduação em Engenharia de Produção, Universidade Federal de Santa Maria, Santa Maria, Brasil
}

\begin{abstract}
Resumo
O presente trabalho objetivou verificar a receptividade e aceitação dos clientes de uma rede de supermercados, em relação à adoção de sacolas retornáveis como estratégia de marketing ambiental. Para tanto, foi realizado um estudo de caso por meio da aplicação de um questionário estruturado. O questionário foi aplicado a uma amostra não probabilística de 150 clientes de uma rede de supermercados situada na cidade de Santa Maria, RS. Os resultados foram positivos quanto à aceitação pelos clientes da substituição das sacolas descartáveis por sacolas retornáveis, entretanto, apesar da aceitação ser alta, a adesão ainda é baixa, uma vez que a maioria dos clientes se esquece de levar as sacolas retornáveis quando vão às compras. Esse resultado demonstra a necessidade de ampliar os investimentos em Educação Ambiental, para conscientizar a população quanto à necessidade e importância da proteção e preservação do meio ambiente.
\end{abstract}

Palavras-chave: sacolas retornáveis ou descartáveis; conscientização; marketing ambiental.

\begin{abstract}
This study aimed to determine the receptivity and acceptance of customers in a supermarket chain in relation to the adoption of reusable bags as a strategy for environmental marketing. Therefore, we conducted a case study by implementing a structured questionnaire. The questionnaire was administered to a non-probability sample of 150 customers of a supermarket chain, located in the town of Santa Maria, RS. The results were positive regarding customer acceptance of replacement of disposable bags for reusable bags, however, despite the acceptance is high, adherence is still low, since most customers forget to take reusable bags when they go shopping. This result demonstrates the need to increase investments in environmental education, to raise awareness about the need and importance of protecting and preserving the environment.
\end{abstract}

Keywords: bags returnable or disposable; awareness, environmental marketing. 


\section{INTRODUÇÃO}

O impacto do desenvolvimento sócio industrial moderno traz consigo riscos de grande consequência. Quatro são as fontes de crise nas quais se enfrenta estes riscos, são elas: o impacto do desenvolvimento social moderno sobre os ecossistemas mundiais; o desenvolvimento da pobreza em larga escala; as armas de destruição em massa com suas possibilidades de violência coletiva e a repressão dos direitos democráticos (SIQUEIRA, 2000). Nesse contexto, o uso e descarte irregular de sacolas plásticas também podem ser considerados como um risco de grande consequência no atual cenário econômico, relacionado principalmente ao processo intenso de industrialização e consumo.

A responsabilidade socioambiental vem criando raízes ao longo do tempo, bem como o respeito das organizações e empresários. Assim, a instituição estudada neste trabalho foi a primeira empresa do ramo de supermercados a utilizar sacolas retornáveis na cidade de Santa Maria, Rio Grande do Sul com intuito de aperfeiçoar sua imagem perante o mercado, além de contribuir para manutenção da qualidade ambiental.

Este trabalho apresenta um estudo desenvolvido com foco na Responsabilidade Socioambiental, relacionando atividades que não somente contribuem com a comunidade, mas também com o meio ambiente, em uma rede de supermercados localizada na cidade de Santa Maria, RS. Santa Maria se educa ambientalmente, e é com essa ideia de maturação de investimento educacional ambiental que essa empresa concretizou a ação da implantação das sacolas retornáveis como diferencial competitivo.

Assim, a busca por novos caminhos é constante podendo melhorar o desenvolvimento empresarial. Dessa forma, este trabalho mostra uma alternativa que há algum tempo vem sendo percorrida por empresas, mas que só recentemente vem ganhando força com a comunicação e na conscientização dos indivíduos, e com o constante crescimento da gerencia de ações de marketing ecológico. Em um cenário competitivo uma rede de Supermercados da cidade de Santa Maria adotou o marketing ecológico, por meio do uso de sacolas retornáveis como forma de contribuir com o desenvolvimento sustentável na região.

A fim de contribuir com informações que possam ser úteis para a empresa estudada, bem como para as demais lojas de supermercados da região, emerge este trabalho, onde os resultados da pesquisa poderão contribuir para a verificação da eficiência do uso das sacolas retornáveis por parte dos consumidores. Conforme Braga (2002), as medidas não estruturais procuram intervir nas causas que podem originar ou agravar um problema, evitando assim que ele ocorra ou permitindo o seu controle. Dessa forma, o trabalho é justificado pela contribuição que oferece tanto à organização, quanto à cidade onde ela encontra-se inserida, uma vez que por meio dessa pesquisa será possível verificar a aceitação e a usabilidade das sacolas retornáveis pelos clientes.

Segundo Souza (2000), as empresas têm buscado diferentes estratégias para melhorar a eficiência ambiental, melhorando a eficiência insumo-produto; tratando os resíduos; desenvolvendo produtos de baixo impacto; utilizando tecnologias limpas; conservando e poupando energia; reaproveitando materiais; reduzindo os resíduos e as emissões. Essas estratégias empresariais, ao mesmo tempo em que melhoram a qualidade ambiental, permitem à empresa viabilizar-se institucionalmente frente às crescentes regulamentações ambientais, bem como manter-se viável economicamente frente a um mercado cada vez mais competitivo, e a um consumidor cada vez mais exigente e a uma sociedade cada vez mais organizada e consciente de seus direitos e deveres.

Para Dias (2007), as organizações percebem no marketing ambiental uma oportunidade que pode ser usada para realizar seus objetivos e também acreditam que tem uma obrigação moral de serem socialmente responsáveis. Tanto a redução de custos que pode advir de uma gestão ambiental adequada, como a melhoria na imagem da empresa e dos produtos, bem como o desenvolvimento de produtos mais saudáveis e ambientalmente menos impactantes, são fatores que resultam em maior competitividade e maior possibilidade de manter ou mesmo de ampliar os mercados e os lucros das empresas (SOUZA, 2000).

Nesse contexto, o presente trabalho pretende identificar se as sacolas retornáveis utilizadas como estratégia de marketing estão sendo aceitas pelos clientes. Para tanto, pretende-se verificar o grau de utilização das sacolas retornáveis, identificando as vantagens obtidas pelos clientes ao utilizar essas sacolas, respondendo, dessa forma, ao problema de pesquisa, que consiste na seguinte questão: as sacolas retornáveis, utilizadas em uma rede de supermercados na cidade de Santa Maria, estão sendo aceitas pelos seus clientes? 


\section{REVISÃO DE LITERATURA}

\section{I. Marketing ambiental}

A atuação do marketing se baseia na busca de soluções racionais para o problema de tornar competitivos produtos que de uma forma ou de outra terão que incorporar no preço os custos ecológicos, o que cria a necessidade do entendimento dos problemas ambientais, que acabarão levando de qualquer forma à mudança de comportamento dos consumidores, das empresas e, consequentemente, do próprio marketing (DIAS, 2007).

Uma das principais modificações no próprio marketing será reconhecer suas próprias limitações e aceitar a necessidade de existência de restrições ao mecanismo de mercado, para manter a sustentabilidade dos negócios que envolvam aspectos relacionados com o meio ambiente. Reconhecer a necessidade da existência de alguma forma de restrição e controle, feita por órgãos governamentais, implica em incorporar essas limitações de forma organizada e definitiva no processo de marketing, tornando-o sustentável.

É importante relembrar que sustentabilidade em marketing significa que toda a empresa deve estar direcionada para a diminuição dos impactos negativos sobre os ecossistemas, e junto a isso continuar atendendo todas as necessidades dos clientes, fornecendo-lhes os produtos que tragam benefícios tanto para eles quanto para a sociedade. Para Dias (2007, p.20), a partir da segunda metade do Século XX, o mundo vivenciou uma explosão consumista marcada pela presença contínua do desperdício e do descarte irregular das sobras, das embalagens e detritos. A partir desse momento histórico as pessoas deixam de ser tratadas como cidadãos e passam a figurar como consumidores.

Essa situação desencadeou vários acontecimentos, e dessa forma se deu o início de uma maior conscientização ambiental. A partir daí, a atividade de marketing foi objeto de duros ataques, sendo apontada como uma das causas essenciais da deterioração do meio ambiente (principalmente a área de comunicação), ao induzir ao consumismo excessivo. Para Dias (2007), o marketing contribuiu com a crise atual do meio ambiente, pois desempenhou um papel central fundamental para impulsionar o consumo não sustentável.

Nesse contexto, o marketing, anteriormente voltado para a satisfação do consumidor, começa a agregar uma filosofia de melhoria da qualidade de vida da sociedade como um todo, o que significa desenvolver estratégias de comunicação por uma melhor qualidade de vida. Assim, conforme Kotler (1998) o objetivo do sistema de marketing deve ser a maximização da qualidade de vida, onde se subentende por qualidade de vida, não apenas a quantidade e a qualidade dos bens e serviços de consumo, mas também a qualidade do meio ambiente.

Dias (2007) relembra que, atualmente, o marketing enfrenta um novo desafio, qual seja: a consideração dos aspectos ambientais, devendo reexaminar suas colocações, técnicas e objetivos para adequá-los a uma nova realidade com um duplo conteúdo, que consiste em captar a evolução da sensibilização da clientela a respeito da deterioração do meio ambiente e antecipar as possíveis influências sobre as necessidades, motivações e hábitos de compra.

É função do marketing ecológico ou ambiental determinar caminhos alternativos para satisfazer as novas exigências do público consumidor de produtos e serviços ambientalmente corretos. Desse modo, o marketing terá um importante papel a desempenhar no futuro, no sentido de promover modos mais sustentáveis de viver e consumir. Além do marketing de novas tecnologias, novos produtos e serviços, será necessária, também, a ampliação do marketing social para tornar as economias mais sustentáveis, promovendo ações que contemplem a reciclagem, a compostagem e a eficiência em energia, enfim, uma forma mais justa de comércio, onde o conceito de sustentabilidade seja promovido e aplicado.

Os conceitos e ideias trazidos destacam a importância do marketing ecológico, que, tendo como base a sustentabilidade vai mais além do que o marketing tradicional. Enquanto o marketing busca entender as necessidades dos clientes e manter um relacionamento construtivo com eles, o marketing ecológico pode ser definido como a construção e a manutenção de relacionamentos sustentáveis com os clientes, dentro de um meio social e natural. Pela criação de valor social e ambiental, o marketing ecológico busca agregar valor ao cliente, baseando-se nas variáveis ambiental, econômica e a social da sustentabilidade. Nesse contexto, entende-se que o marketing ambiental pode contribuir significativamente para frear os efeitos dos riscos de grande proporção, principalmente no que se refere à utilização de sacolas retornáveis nos supermercados para o acondicionamento dos produtos. 


\subsection{GestÃo AMBIENTAL}

Uma das modificações mais significativas observadas nos últimos anos foi a mudança da visão e da cultura organizacional em relação ao meio ambiente. A indústria, em nível mundial, está consciente que sua sobrevivência no atual cenário econômico perpassa a necessidade de adesão a alguma forma de desenvolvimento sustentável, adotando novas metodologias de produção. Assim, uma metodologia de Produção Mais Limpa (economizando energia, matérias-primas, e gerando menos resíduos de poluição), por meio da implantação de Sistemas de Gestão Ambiental e social, fazendo uso da Responsabilidade Social Corporativa, pode melhorar significativamente a imagem organizacional frente aos consumidores. Nesse sentido, a atitude empresarial com relação ao meio-ambiente torna-se cada vez mais proativa, e atualmente muitas empresas apresentam um desempenho ambiental superior ao exigido pelas normas regulamentadoras (ALMEIDA et al., 2004).

A economia do meio ambiente concentra-se excessivamente na análise dos custos da recuperação ambiental e na alocação destes custos, de acordo com o princípio do poluidor pagador. Assim, na medida em que a responsabilidade se traduz por um custo do produto final, a competitividade da empresa é afetada. Conforme Kraemer $(2009$, p. 3)

[...] O meio ambiente da empresa é constituído por diversas formas de relacionamento, considerando as disciplinas gerenciais, as técnicas e o processo de produção junto às instalações e ao meio interno e externo, incluindo-se também a relação entre mercado, cliente, fornecedores, comunidade e consumidor. Neste sentido, o gerenciamento ambiental não pode separar e nem ignorar o conceito de ambiente empresarial em seus objetivos, pois o desenvolvimento deste conceito possibilita melhores resultados nas relações internas e externas, com melhorias na produtividade, na qualidade e nos negócios.

A gestão ambiental é a forma pela qual uma organização, pública ou privada, se mobiliza em busca da qualidade ambiental desejada. Assim, por meio da gestão ambiental pública, o governo pode adotar instrumentos e mecanismos para gerenciar atividades específicas desenvolvidas por certos segmentos industriais, que trazem consequências indesejáveis ao meio ambiente. São estes mesmos mecanismos, como as legislações e regulamentações, que as empresas privadas devem lidar em sua gestão ambiental (VILLASBÔAS, 1998).

Nesse contexto, apesar de todos os problemas mundiais relacionados ao controle da poluição, as empresas buscam cada vez mais estar à frente de seus concorrentes, e com isso, sua responsabilidade ambiental e social aumenta cada vez mais. Assim, a gestão ambiental e a responsabilidade social, conjuntamente com o Marketing ambiental, deixam de ser políticas corretas para fazer parte da gestão estratégica, onde as empresas caminham em busca de sucesso organizacional.

\section{METODOLOGIA DA PESQUISA}

O presente trabalho caracteriza-se como sendo um trabalho quantitativo e qualitativo, pois foi realizado por um estudo de caso, utilizando-se como ferramenta de coleta de dados a aplicação de um questionário com perguntas fechadas. Essa situação promoveu a formação de uma base de dados quantitativa sobre o problema em análise. Na sequência, a análise dos dados quantitativos foi realizada sem a utilização de procedimentos estatísticos, de forma subjetiva. O método de estudo do caso empregado fundamentou-se em quatro fases, conforme explica Lopes (1990): definição do objetivo, observação, descrição e interpretação, evidenciando-se os resultados da pesquisa por meio de registros em arquivos, entrevistas e observações diretas.

A ferramenta de coleta de dados, composta por um questionário estruturado com 13 questões fechadas, foi aplicada a uma amostra não probabilística de 150 clientes de uma Rede se Supermercados localizada na cidade de Santa Maria, Região Central do estado do Rio Grande do Sul (RS). A aplicação do questionário ocorreu durante uma semana, sendo os respondentes escolhidos aleatoriamente, principalmente em função da acessibilidade e disponibilidade de tempo para responder o questionário.

Segundo Domingues (2005), uma população ou universo, no sentido geral, é um conjunto de elementos com pelo menos uma característica comum. Essa característica deve delimitar, inequivocamente, quais elementos pertencem ou não à população. Para o mesmo autor, a amostra é um subconjunto, necessariamente finito de uma população, no qual todos os elementos serão examinados para efeito da realização do estudo estatístico desejado. 


\section{ANÁLISE DOS RESULTADOS}

Visando atingir os objetivos da pesquisa, foi aplicado um questionário contendo 13 questões fechadas para 150 clientes, sendo os clientes escolhidos aleatoriamente, em função da disponibilidade para responder o questionário. Dessa forma, na Tabela 01 foi demonstrado o gênero dos entrevistados.

\begin{tabular}{lcc}
\multicolumn{3}{c}{ Tabela 01 - Gênero } \\
\hline Sexo & Frequência & Porcentagem \\
\hline Masculino & 52 & $34,67 \%$ \\
Feminino & 98 & $65,33 \%$ \\
\hline Total & 150 & $100,00 \%$ \\
Fonte: Dados da pesquisa & &
\end{tabular}

Conforme demonstrado na Tabela 01, a maioria dos participantes da pesquisa são mulheres, onde estas representam $65,33 \%$, e os homens representam $34,67 \%$ do total dos entrevistados. Já na Tabela 02 pode-se observar as informações a respeito da idade dos entrevistados.

\begin{tabular}{lcc} 
& Tabela 02 - Idade & \\
\hline Faixa etária & Frequência & Porcentagem \\
\hline Até 20 anos & 24 & $16,00 \%$ \\
21 a 30 anos & 49 & $32,67 \%$ \\
31 a 40 anos & 27 & $18,00 \%$ \\
41 a 60 anos & 46 & $30,67 \%$ \\
mais de 60 anos & 4 & $2,67 \%$ \\
Total & 150 & $100,00 \%$
\end{tabular}

Com relação à idade, dos 150 entrevistados $16 \%$ apresentam idade de até 20 anos, $32,67 \%$ têm de 21 a 30 anos, $18 \%$ têm de 31 a 40 anos, $30,67 \%$ têm de 41 a 60 anos e a minoria de $2,67 \%$ apresenta idade superior a 60 anos.

$\mathrm{Na}$ Tabela 03 é possível verificar como o entrevistado ficou sabendo das sacolas retornáveis da rede de supermercados que ele frequenta. Os dados demonstram que as pessoas ficaram sabendo da existência das sacolas retornáveis da Rede de Supermercados, principalmente, por meio de propaganda na TV aberta $(63,33 \%)$ ou, em segundo lugar, por que já eram clientes da Rede (17,33\%) e conheceram a sacola retornável no próprio supermercado. Estes dados demostram que o veículo de marketing mais promissor para a rede atingir o público alvo na cidade de Santa Maria, RS, é a propaganda na TV aberta, uma vez que os dados sugerem a captação de novos clientes.

Tabela 03 - Como ficou sabendo do uso das sacolas retornáveis pelo supermercado

\begin{tabular}{lcc}
\hline Meios & Frequência & Porcentagem \\
\hline Rádio & 10 & $6,67 \%$ \\
Televisão & 95 & $63,33 \%$ \\
Internet & 6 & $4,00 \%$ \\
Amigos & 13 & $8,67 \%$ \\
No próprio supermercado da Rede & 26 & $17,33 \%$ \\
\hline Total & 150 & $100,00 \%$ \\
\hline
\end{tabular}

Fonte: Dados da pesquisa

Conforme os dados da Tabela 4 observa-se a aceitação dos entrevistados quanto à adoção de 
sacolas retornáveis. De acordo com os dados apresentados, dos 150 entrevistados, 54\% têm uma aceitação totalmente favorável ao uso das sacolas e $40 \%$ aceitam parcialmente. Estes dados confirmam a hipótese de que as sacolas retornáveis foram bem aceitas pelos clientes da rede de supermercado.

Tabela 04 - A aceitação das sacolas retornáveis

\begin{tabular}{lcc}
\hline Aceitação & Frequência & Porcentagem \\
\hline Total & 81 & $54,00 \%$ \\
Parcial & 60 & $40,00 \%$ \\
Nula & 9 & $6,00 \%$ \\
Total & 150 & $100,00 \%$ \\
\hline Fonte: Dados da pesquisa & &
\end{tabular}

Na Tabela 05 demonstra-se o grau de utilização das sacolas retornáveis pelos consumidores entrevistados. Conforme os dados apresentados sobre a utilização das sacolas retornáveis, $20 \%$ afirmaram que usam a sacola sempre; $25,33 \%$ disseram que às vezes a usam; $22 \%$ afirmaram que a usam raramente; e $32,67 \%$ dos entrevistados disseram que nunca a usaram. Estes dados confirmam que a maioria dos clientes do supermercado não utilizam as sacolas retornáveis regularmente. Entretanto, se forem somados os percentuais dos que utilizam, ainda que não regularmente, se tem que mais de $65 \%$ dos entrevistados já fizeram uso das sacolas retornáveis.

Tabela 05 - Utiliza as sacolas retornáveis

\begin{tabular}{lcc}
\hline Alternativas & Frequência & Porcentagem \\
\hline Sempre & 30 & $20,00 \%$ \\
Às vezes & 38 & $25,33 \%$ \\
Raramente & 33 & $22,00 \%$ \\
Nunca & 49 & $32,67 \%$ \\
Total & 150 & $100,00 \%$ \\
\hline Fonte: Dados da pesquisa & &
\end{tabular}

Segundo os dados analisados, dos 150 entrevistados, apenas 16,13\% afirmaram que substituíram completamente as sacolas descartáveis pelas sacolas retornáveis, a grande maioria $(51,61 \%)$ disseram que fizeram a substituição em parte (Tabela 06). Esses dados demonstram que as pessoas estão abertas a mudanças, mas que essa mudança de hábitos passa por um processo de educação ambiental, onde as informações ambientais devem ser divulgadas de forma a conscientizar a população para a importância da contribuição que cada indivíduo pode dar para a manutenção da qualidade ambiental.

Tabela 06 - Substituição das sacolas descartáveis pelas retornáveis

\begin{tabular}{lcc}
\hline Alternativas & Frequência & Porcentagem \\
\hline Muito pouco & 40 & $32,26 \%$ \\
Em parte & 64 & $51,61 \%$ \\
Completamente & 20 & $16,13 \%$ \\
Total & 124 & $100,00 \%$ \\
Fonte: Dados da pesquisa & &
\end{tabular}

Os resultados demostraram que dos 150 entrevistados apenas 1,33\% não acha importante o uso das sacolas retornáveis, enquanto a grande maioria de $57,33 \%$ acredita que seja muito importante que a comunidade use as sacolas retornáveis (Tabela 07). 
Tabela 07 - Como avalia a importância do uso das sacolas retornáveis pela comunidade

Alternativas $\quad$ Frequência $\quad$ Porcentagem

\begin{tabular}{lcc}
\hline Ruim & 2 & $1,33 \%$ \\
Razoável & 3 & $2,00 \%$ \\
Bom & 47 & $31,33 \%$ \\
Ótimo & 86 & $57,33 \%$ \\
Não sei avaliar & 12 & $8,00 \%$ \\
\hline Total & 150 & $100,00 \%$ \\
\hline Fonte: Dados da pesquisa & &
\end{tabular}

Outra questão levantada foi com relação às vantagens do uso de sacolas retornáveis, a maioria $(62 \%)$ dos entrevistados acredita que existem vantagens ao usar as sacolas retornáveis, enquanto que $38 \%$ dos entrevistados não veem vantagens ao usá-la. Dos que acharam vantajoso o uso das sacolas retornáveis, todos enunciaram como principal vantagem à diminuição da poluição ambiental (Tabela 08). Esses dados reforçam a questão da necessidade de ampliar o acesso à educação ambiental.

Tabela 08 - Vantagens ao usar as sacolas retornáveis

\begin{tabular}{lcc}
\hline Vantagens & Frequência & Porcentagem \\
\hline \multirow{2}{*}{ Sim } & 93 & $62,00 \%$ \\
Não & 57 & $38,00 \%$ \\
Total & 150 & $100,00 \%$ \\
\hline
\end{tabular}

Fonte: Dados da pesquisa

Na Tabela 09 é demonstrado se o consumidor lembra-se de levar a sacola ao supermercado quando vai fazer suas compras.

Tabela 09 - Lembrança de levar as sacolas retornáveis quando vai ao supermercado

\begin{tabular}{lcc}
\hline Colaboração & Frequência & Porcentagem \\
\hline Sempre & 25 & $16,67 \%$ \\
Às vezes & 61 & $40,67 \%$ \\
Nunca & 64 & $42,67 \%$ \\
Total & 150 & $100,00 \%$
\end{tabular}

Fonte: Dados da pesquisa

Conforme os dados analisados, apenas $16,67 \%$ dos entrevistados afirmaram que se lembram de levar as sacolas retornáveis ao mercado, enquanto que 40,67\% afirmaram que apenas às vezes lembram e $42,67 \%$ disseram que nunca lembram de levar as sacolas retornáveis para fazer compras.

Por meio dos dados da Tabela 10 fica demonstrado se os consumidores acreditam que a empresa está colaborando com a preservação do meio ambiente por meio da utilização das sacolas retornáveis.

De acordo com os dados obtidos da Tabela 10, apenas $2 \%$ dos entrevistados pensam que a empresa não contribui e nada com o meio ambiente adotando essa prática, enquanto que $30 \%$ entendem que ela esta ajudando pouco o meio ambiente e a grande maioria (68\%) afirmaram que a empresa está colaborando com a preservação do meio ambiente. 
Tabela 10 - A empresa está colaborando com a preservação do meio ambiente

\begin{tabular}{lcc}
\hline Colaborou & Frequência & Porcentagem \\
\hline Nada & 3 & $2,00 \%$ \\
Pouco & 45 & $30,00 \%$ \\
Muito & 102 & $68,00 \%$ \\
Total & 150 & $100,00 \%$ \\
\hline Fonte: Dados da pesquisa & &
\end{tabular}

Conforme a Tabela 11, dos 150 entrevistados, 52\% afirmaram que se disponibilizariam a pagar para usar as sacolas retornáveis, e $48 \%$ dos entrevistados afirmaram que não pagariam para usar as sacolas retornáveis.

Tabela 11 - Se disponibilizaria a pagar pela sacola retornáveis

\begin{tabular}{lcc}
\hline Alternativas & Freqüência & Porcentagem \\
\hline Sim & 78 & $52,00 \%$ \\
Não & 72 & $48,00 \%$ \\
\hline Total & 150 & $100,00 \%$ \\
\hline
\end{tabular}

Fonte: Dados da pesquisa

Desse modo, os resultados da pesquisa apontam que a aceitação das sacolas retornáveis é positiva, entretanto é necessário investir mais em conscientização e educação ambiental para que os clientes passem a consumir mais conscientemente.

\section{CONSIDERAÇÕES FINAIS}

Imersas em um tempo onde cada vez mais o Ser Humano depreda o Meio Ambiente, consome os recursos naturais e elimina seus resíduos de forma irregular, algumas empresas estão adotando práticas ecologicamente corretas, com o objetivo de melhorar a sua imagem frente ao mercado, diminuir custos, mas principalmente em função de promover melhorias ambientais. Assim, as redes de supermercados desenvolveram as chamadas sacolas retornáveis para substituir as sacolas plásticas descartáveis. Essas últimas, por serem extremamente prejudiciais ao meio ambiente, causando impactos de grandes proporções ao planeta, tendem a ser substituídas gradualmente por embalagens alternativas, ambientalmente menos prejudiciais.

Este trabalho verificou por meio de aplicação de um questionário estruturado, que as sacolas retornáveis utilizadas como estratégia de marketing ambiental estão sendo aceitas pelos clientes da rede de supermercados estudada. No entando, apesar da aceitação ser alta, a adesão ainda é baixa, uma vez que a maioria dos clientes aceita a substituição das sacolas, mas na maioria das vezes se esquece de levar, na hora das compras, as sacolas retornáveis e acaba voltando do supermercado com as antigas e antiquadas sacolas descartáveis.

Portanto, o marketing ambiental por meio da adoção de campanhas que aumentem a adesão à utilização de sacolas retornáveis pode contribuir significativamente para frear os avanços dos riscos de grande proporção, no que se refere ao uso e descarte inadequado de sacolas plásticas principalmente na cadeia de supermercados. Visando que essa prática seja disseminada entre a população é necessário maiores investimentos em Educação Ambiental, de forma a conscientizar a população para necessidade de uma mudança de hábitos, que melhore a qualidade e as condições ambientais, onde cada um deve fazer a sua parte. 


\section{REFERÊNCIAS}

ALMEIDA, J. R.; MELLO, C. S.; CAVALCANTI, Y. Gestão Ambiental: Planejamento, avaliação, implantação, operação e verificação. Rio de Janeiro: Thex Editora, 2000.

BRAGA, B. et al. Introdução à engenharia ambiental. São Paulo: Prentice Hall, 2002.

DIAS, R. Marketing ambiental: ética, responsabilidade social e competitividade nos negócios; São Paulo: Atlas, 2007.

DOMINGUES, C. A. Estatística aplicada às ciências militares. Rio de janeiro: Escola de Aperfeiçoamento de Oficiais, 2005.

KOTLER, P. Administração de marketing: analise, planejamento, implementação e controle; tradução Ailton Bomfim Brandão. 5.ed. São Paulo: Atlas, 1998.

KRAEMER, M. E. Gestão ambiental: um enfoque no desenvolvimento sustentável, 2009. Disponível em: < http://www.ambientebrasil.com.br/gestao/des sustentavel.doc>. Acesso em: 02 abr. 2013.

LAKATOS, E. M.; MARCONI, M. A. Metodologia do trabalho científico: procedimentos básicos, pesquisas bibliográfica, projeto e relatório, publicações e trabalhos científicos. 6. ed. São Paulo: Atlas, 2005.

LOPES, M. L. V. Pesquisa em comunicação: formulação de um modelo metodológico. São Paulo: Loyola, 1990.

SIQUEIRA, H. S. G. Jornal "A Razão" - 07.12.2000 / "Pós-Modernidade", 2000. Disponível em: < http:// www.angelfire.com/sk/holgonsi/>. Acesso em: 19 de maio de 20123.

SOUZA, R. S. Entendendo a questão ambiental. Santa Cruz do Sul: Ed.Unisc, 2000.

VILLASBÔAS, P. P. A importância da regulamentação da biossegurança como um instrumento de gestão ambiental, 1998 Disponível em: <http://www.eps.ufsc.br/disserta98/paula/> . Acesso em: 05 abr. 2013. 